\title{
Transit and residence times in the Adriatic Sea surface as derived from drifter data and Lagrangian numerical simulations
}

\author{
P.-M. Poulain and S. Hariri \\ Istituto Nazionale di Oceanografia e di Geofisica Sperimentale (OGS), Trieste, Italy \\ Correspondence to: P.-M. Poulain (ppoulain@ogs.trieste.it) \\ Received: 17 December 2012 - Published in Ocean Sci. Discuss.: 24 January 2013 \\ Revised: 27 June 2013 - Accepted: 2 July 2013 - Published: 6 August 2013
}

\begin{abstract}
Statistics of transit and residence times in the Adriatic Sea surface, a semi-enclosed basin of the Mediterranean, are estimated from drifter data and Lagrangian numerical simulations. The results obtained from the drifters are generally underestimated given their short operating lifetimes (half life of $\sim 40$ days) compared to the transit and residence times. This bias can be removed by considering a large amount of numerical particles whose trajectories are integrated over a long time (750 days) with a statistical advection-dispersion model of the Adriatic surface circulation. Numerical particles indicate that the maximum transit time to exit the basin is about 216-260 days for particles released near the northern tip of the Adriatic, and that a particle entering on the eastern Otranto Channel will typically exit on the other side of the channel after 170-185 days. A duration of 150-168 days is estimated as the residence time in the Adriatic Basin.
\end{abstract}

\section{Introduction}

Transport by ocean currents plays a crucial role in many scientific and applied marine issues. For instance, basin-scale circulation and mesoscale currents are responsible for the advection and mixing of water mass properties, and hence control their distribution. Near-coastal currents contribute significantly to the mixing of coastal waters with the open sea. In the coastal zone and semi-enclosed seas, transport by surface currents are even more important due to the variety of flotsam and jetsam, like debris, pollutants, oil spills, persons lost at sea, etc., encountered in the vicinity of populated coasts and highly navigated areas (Jordi et al., 2006; Davidson et al., 2009). Ocean currents also play a major role for the transport of eggs and larvae (Hare et al., 2002), and can have a significant effect on marine animal migration patterns (for instance for turtles in the Mediterranean, Hays et al., 2010).

A useful indicator for water mass mixing, and biogeochemical processes, is the residence time in a basin, defined here as the mean time that a water particle stays in the basin. The concept of residence time has been described and applied in several coastal areas and semi-enclosed seas (see for instance, Takeoka, 1984; Buffoni et al., 1997; and Falco et al., 2000). The transit time probability density function (pdf) is a diagnostic commonly used to summarize the rate at which water particles are transported from one region to another via a multiplicity of pathways (Holzer and Hall, 2000). The first moment of this pdf, referred to as the mean transit time, has become an important transport diagnostic commonly used by both the observational and modeling communities.

Observations of ocean currents and dispersion with surface drifters have been used effectively to describe and quantify the transport characteristics from the global scale (Niiler et al., 2003) to marginal seas (Falco et al., 2000; Lacorata et al., 2001) and selected coastal areas (Haza et al., 2010; Veneziani et al., 2007, Choukroun et al., 2010). In particular, the Adriatic Sea, a semi-enclosed basin of the Mediterranean, connected to the Ionian Sea through the Otranto Channel (Fig. 1), has been extensively studied over the last decades with surface drifters. The mean surface circulation, its seasonal and mesoscale variability, and the role of the wind-forcing have been investigated by Poulain (2001) and Ursella et al. (2006). Adriatic surface transport properties have been studied by Falco et al. (2000). Relative dispersion as measured by drifters has been addressed by Lacorata et al. (2001) and the statistical prediction of drifter 
trajectories has been discussed by Castellari et al. (2001) and Veneziani et al. (2007).

In this paper, the entire surface drifter dataset available in the Adriatic Sea (1990-2007) is used in concert with a Lagrangian circulation model to estimate the surface residence time in the basin, and surface transit times between different locations within the semi-enclosed sea. In particular, the transit times before leaving the Adriatic via the western Otranto Channel and the transit times after entering the basin through the eastern Otranto Channel are considered in order to investigate the exchange between the two sub-basins. Two major problems arise when using real drifters to estimate residence or transit times: (1) the finite lifetime ("mortality") of the drifters and the scarcity of drifter data can introduce significant random and bias errors. The statistical results can also be dependent upon the specific deployment locations selected; (2) the trajectories of surface drifter can be directly affected by the winds and waves, and as a result, deviate from those of real water particles. The first problem can be assessed and somehow alleviated by using a statistical model, whose parameters are derived from the drifter data themselves, to generate the tracks of many and long-lived numerical particles, from which the statistics are calculated. For the second problem, we can correct the drifter velocities (see Poulain et al., 2009) to remove the direct-wind effect, which is not easy in the Adriatic where winds are highly variable both in space and time, but it is impossible to reconstruct windindependent drifter tracks and to estimate the transport properties based on them. As a result, caution is needed when applying our results to surface water transports, but they are certainly useful estimates for debris, oil spills and living or dead persons (search-and-rescue operations), which also are directly affected by the winds. Our results cannot be used to study 3-D transport of water masses within the Adriatic Sea since the drifter observations and numerical simulations only concern surface currents.

\section{Data and methods}

\subsection{Data}

Surface drifters were used in the Adriatic Sea since 1990 to study the spatial structure and temporal variability of its circulation (Poulain, 2001 and references therein; Ursella et al., 2006). In total 358 satellite-tracked drifters were operated in the Adriatic Basin between 25 August 1990 and 14 March 2007. All drifters used the satellite Argos system for the telemetry of the data and their localization. Some drifters were equipped with a global positioning system (GPS). The majority of the drifters were CODE drifters designed to measure the currents in the first meter under the sea surface (Davis, 1985; Poulain, 1999) with an accuracy of less than $3 \mathrm{~cm} \mathrm{~s}^{-1}$ (see Poulain et al., 2012 and references therein). Due to stranding and removal by seafarers, Adriatic
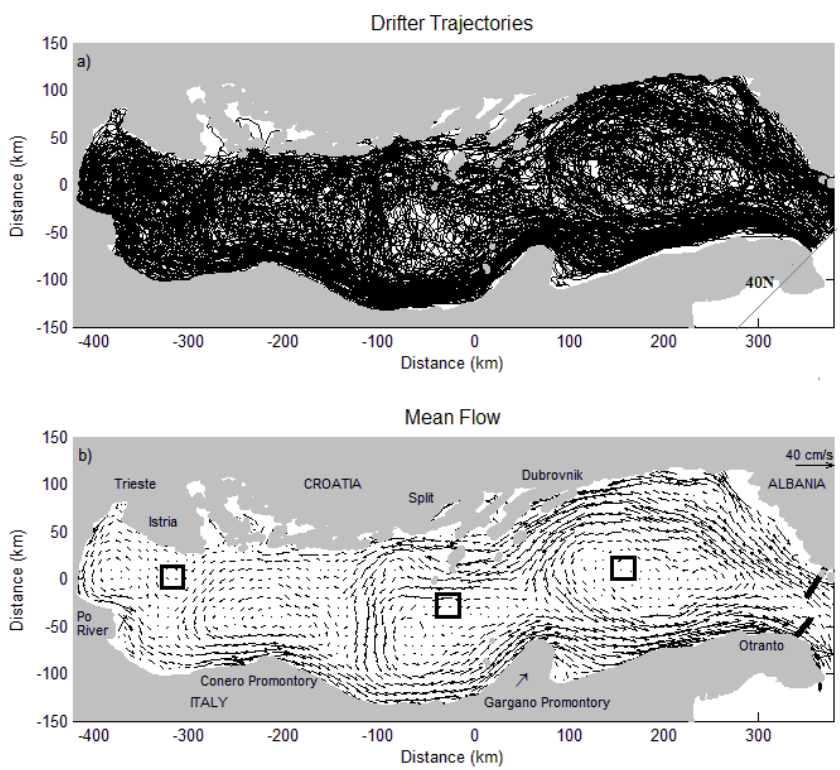

Fig. 1

Fig. 1. (a) Drifter trajectories in the Adriatic Sea for the period August 1990-March 2007. (b) The mean flow obtained by averaging the drifter data in circular bins of $10 \mathrm{~km}$ radius. Selected geographical names and two sections in the vicinity of the Otranto Channel are shown, as well as the three squared areas considered for the transit time pdfs shown in Figs. 2 and 4.

drifters are rather short lived. Indeed they have a typical half life of 35-40 days (Poulain, 2011; Ursella et al., 2006).

The raw drifter positions were edited to remove spikes and outliers, filtered to remove high-frequency currents (tidal and inertial currents) and interpolated at fixed $6 \mathrm{~h}$ intervals (Hansen and Poulain, 1996; Poulain, 2001). Velocities were calculated as finite differences between successive positions. The geographic drifter positions were transformed into distances from a central point (longitude $16^{\circ} 15^{\prime} \mathrm{E}$, latitude $42^{\circ} 45^{\prime} \mathrm{N}$ ) after a counter-clockwise rotation of $45^{\circ}$ of the Adriatic Sea. All the results in this paper are presented in this reference system.

\subsection{Methods}

The mean surface flow in the Adriatic Sea was computed by averaging all the drifter velocities in circular bins of $10 \mathrm{~km}$ radius organized on a uniform grid with $10 \mathrm{~km}$ cell size (Fig. 1). Only bins with at least 5 observations were considered for the pseudo-Eulerian statistics. Similar drifter velocity averages were computed by Poulain $(1999,2001)$ and Ursella et al. (2006).

A Lagrangian statistical model, whose parameters are derived from the data, was used to generate numerical particles. It is based on the assumption that the transport of a particle can be separated into two processes: the advection 
due to the mean velocity field $(\boldsymbol{U})$ and the turbulent transport $\left(\boldsymbol{u}^{\prime}\right)$ that is characterized from the diffusivity $(K)$ (Falco et al., 2000). Bold italic symbols represent 2-D vectors. The mean flow $\boldsymbol{U}$ was taken as the one estimated from the real drifters (pseudo-Eulerian average). The model is a "random flight model" (Thompson, 1986; Falco et al., 2000) and its equations are in the zonal direction ( $x$ coordinate):

$\mathrm{d} x=\left(U+u^{\prime}\right) \cdot \mathrm{d} t$,

$\mathrm{d} u^{\prime}=-\left(1 / T_{\mathrm{L} x}\right) \cdot u^{\prime} \cdot \mathrm{d} t+\sqrt{\left(\sigma_{x}^{2} / T_{\mathrm{L} x}\right)} \cdot \mathrm{d} w$,

where $\sigma_{x}^{2}$ is the velocity variance, $T_{\mathrm{L} x}$ is the Lagrangian integral timescale (for $t \gg T_{\mathrm{L} x}, T_{\mathrm{L} x}=K / \sigma_{x}^{2}$ ) and $\mathrm{d} w$ is a random increment from a normal distribution with zero mean and second order moment. The same equations are valid for the meridional direction ( $y$ coordinate). The time step $\mathrm{d} t$ was taken as $1 \mathrm{~h}$ and the model parameters were taken from Poulain (2001): $\sigma_{x}^{2}=106 \mathrm{~cm}^{2} \mathrm{~s}^{-2}, \sigma_{y}^{2}=70 \mathrm{~cm}^{2} \mathrm{~s}^{-2}, T_{\mathrm{L} x}=$ $T_{\mathrm{L} y}=1.6$ days (a mean value between 2.1 and 1.1 days for the along- and across-basin directions, respectively). In this simple model, we assume that the surface velocity fluctuations in the Adriatic Sea, which include variability at mesoscale, synoptic, seasonal and interannual scales, and also a contribution due to geographical inhomogeneities, can be considered as 2-D turbulence characterized by the above-mentioned parameters. Each numerical particle trajectory was obtained by integrating Eqs. (1) and (2) with a different realization of the turbulent process and interpolating $U$ between grid points using a Runge-Kutta fourth-order Lagrangian interpolation scheme. Eight numerical particles were "deployed" at each grid point of the grid with $10 \mathrm{~km}$ resolution and spanning the entire Adriatic, so that, in total, 1000 particles were integrated over a period of 750 days. The choice of 1000 numerical particles is quite arbitrary, it is however important that it is larger than the number of real drifters in order to obtain robust statistical results. Thanks to a reflection condition, the numerical particles approaching the coast are bouncing back inside the basin. They can exit at the Otranto Channel but are not considered if they re-enter the Adriatic Sea.

Two sections were chosen in the Otranto Channel (Fig. 1b). The western one corresponds to the outflow and connects the Italian coast at point $(341.1 \mathrm{~km},-70.8 \mathrm{~km})$ to point $(365.9 \mathrm{~km},-43.2 \mathrm{~km})$ where the speed of the mean flow derived from the drifters is equal to zero. The second section on the eastern side connects the Albanian coast $(371.3 \mathrm{~km}, 13.82 \mathrm{~km})$ point to point $(350 \mathrm{~km},-30 \mathrm{~km})$ where the mean flow is nil. It corresponds to the inflow into the Adriatic Sea. The trajectories of real drifters and numerical particles exiting through the Otranto Channel section were selected. After having divided the basin in $25 \mathrm{~km} \times 25 \mathrm{~km}$ squares, the pdfs of the transit times to exit the Adriatic Sea (i.e., to cross the western Otranto section), its mean and standard deviation and the number of observations were calculated in each square. Likewise, the transit time pdfs of the drifters and numerical particles entering the basin through the eastern Otranto section were calculated for all the squares in the basin. Note that if many $6 \mathrm{~h}$ observations of the same drifter are included in a given square, all the sub-tracks initiating from these observations were considered to compute the transit time statistics. Given the fact that the Lagrangian integral scale is 1-2 days, the sub-sampling at every $6 \mathrm{~h}$ might appear exaggerated. However, averaging over many dependent sub-tracks does not affect the statistical results and does not introduce any bias in the estimated mean times. Note that in this paper, the transit time is defined as the time a particle takes to move from one area to another area in the Adriatic Sea. In particular, the area can be a $25 \mathrm{~km}$ square in the basin or a section in the Otranto Channel. The transit time of particles after their entrance via the Otranto Channel to a given area of the Adriatic Sea is equivalent to the "age" (e.g., see definition in Monsen et al., 2002).

In this work, the (basin average) residence time is defined as the average time spent by a tracer particle in the basin. The normalized population in the basin, $C(t)$, and its residence time, $T$, are defined by Buffoni et al. (1997):

$C(t)=\int_{\Omega} c(t, x) \mathrm{d} x$

$T=\int_{0}^{\infty} C\left(t^{\prime}\right) \mathrm{d} t^{\prime}$,

where $c(t, x)$ is the average normalized tracer concentration at point $x$ and time $t$ (after an uniform initial release in the entire basin), and $\Omega$ represents the basin. $C(t)$ and $T$ can also be defined in the Lagrangian framework as

$C(t)=\frac{N(t)}{N(0)}$,

$T=\lim T^{*}$

$t \rightarrow \infty$,

$T^{*}=\frac{t N(t)}{N(0)}+\sum_{i=1}^{N_{\mathrm{e}}(t)} \frac{t_{\mathrm{e} i}}{N(0)}$,

where $N(0)$ is the number of tracer particles initially deployed in the basin, $N(t)$ is the number of particles at time $t, \mathrm{Ne}$ is the number of particles that have already escaped the basin at time $t$, and $t_{\mathrm{e} i}$ is the escape time of the $i^{\text {th }}$ particle. Note that for the calculation of the residence time the southern boundary of the Adriatic Sea in the Otranto Channel is taken as the 40th parallel north. 
Table 1. Summary of transit and residence time statistics using numerical particles.

\begin{tabular}{|c|c|c|c|c|c|}
\hline Cases & $\begin{array}{l}\text { Integration } \\
\text { Time }\end{array}$ & $T^{*}$ & $\begin{array}{l}\text { Transit Time } \\
\text { (northern } \\
\text { Adriatic- } \\
\text { Otranto) }\end{array}$ & $\begin{array}{l}\text { Transit Time } \\
\text { (Otranto- } \\
\text { Otranto) }\end{array}$ & $\begin{array}{l}\text { Number of particles } \\
\text { exiting Adriatic }\end{array}$ \\
\hline No turbulence & 750 days & 250 days & 100 days & 130 days & 678 \\
\hline $\begin{array}{l}\text { Turbulence } \\
\text { Poulain (2001) }\end{array}$ & 750 days & 166 days & 250 days & 180 days & 986 \\
\hline $\begin{array}{l}\text { Turbulence } \\
\text { Poulain (2001) }\end{array}$ & 1000 days & 168 days & 260 days & 185 days & 998 \\
\hline $\begin{array}{l}\text { Turbulence } \\
\text { Ursella et } \\
\text { al. (2006) }\end{array}$ & 750 days & 150 days & 216 days & 170 days & 995 \\
\hline
\end{tabular}

\section{Results}

The mean surface circulation in the Adriatic Sea estimated from the real drifters (Fig. 1) shows the basin-scale cyclonic circulation with Ionian waters entering on the eastern flank of the Otranto Channel and flowing northwestward off Albania and Croatia as the Eastern Adriatic Current (EAC). The basin-scale circulation is actually composed of 3 cyclonic cells with waters from the EAC splitting and crossing the basin at the levels of the northern walls of the southern and central Adriatic Pits, and in the vicinity of the Istrian Peninsula (Poulain, 2001; Poulain and Cusman-Roisin, 2001). A forth cyclonic loop appears near the northern end of the basin. Along the Italian coast, a strong coastal current, the Western Adriatic Current (WAC), flows towards the southeast and the surface waters eventually exit on the western side of the Otranto Channel.

Example pdfs of the transit times of numerical particles between areas selected in the northern, central and southern Adriatic (see squares in Fig. 1b) and the western Otranto Channel are shown in Fig. 2. In total, more than 1800 tracks connect the selected areas to the Otranto section, including all the sub-tracks of the same numerical particle as long as the $6 \mathrm{~h}$ observations are localized in the departure squared area. The distributions have mean values of about 210, 168 and 121 days, respectively for the areas in the northern, central and southern Adriatic. The pdfs are not Gaussian and are significantly skewed with a long "tail" corresponding to long transit times. The maximum transit time is about 737 days, which is less than the integration times of the numerical particles (750 days). Thus we can assume negligible effect of the finite lifetime on the transit time statistics. With real drifters, the number of tracks is drastically reduced (39-242) and the mean transit times are 153, 58 and 52 days, whereas the maximum transit time is 240 days (for the northern box).

Despite the above-mentioned problems of nonGaussianity and limited number of real drifter observations, it is interesting to look at the spatial distribution of the mean transit times to exit through the Otranto Channel as estimated from both real and numerical particles (Fig. 3). The tracks of all the real drifters that exited the Adriatic are also shown. Along the Italian coast, in the WAC, the mean transit time of numerical particles is less than 90 days south of Gargano, and less than 140 days south of Conero. In front of the Po River it is about 190 days, and stays above this value on the eastern side of the basin as far south at the eastern Otranto Channel. In the mean sense, a surface particle entering at Otranto stays in the Adriatic about 180 days before exiting on the other side of the channel. The transit time standard deviation (not shown) varies between 65 days (near the exit) and 135 days (in most of the basin). If the same statistics are computed with the real drifters, the spatial distribution of mean transit time is very different and values are systematically smaller: it is maximal off the Istrian Peninsula ( $>200$ days) but it is less than 100 days in most of the Adriatic. Specifically, it is about 80 days near Conero and 55 days near Gargano.

Let us now consider the transit times of surface drifters and numerical particles after their entrance in the eastern Otranto Channel. The transit time pdfs to reach the selected squared areas depicted in Fig. 1b are shown in Fig. 4. Compared to the distributions considered before (Fig. 2) the number of tracks is considerably reduced: only 175 (62) numerical (real) tracks reach the square in the southern Adriatic. Mean transit times for numerical particles range in 129-225 days, compared to 27-62 for real drifters.

The tracks of the real drifters entering the Adriatic Sea via the western Otranto section, and the mean transit times to reach all the areas of the Adriatic with real and numerical drifters are displayed in Fig. 5. The mean transit time from the Otranto Channel is less than 135 days in the EAC as far north as the Dalmatian Islands in front of Split, Croatia. It reaches 180 days in the vicinity of the Istrian Peninsula. Maximal values larger than 250 days are found in the open central Adriatic. In the WAC, values range between 150 and 230 days. In agreement with the results shown in Fig. 3c, the mean transit time from the eastern to the western sides of the Otranto Channel is about 180 days with standard deviation 

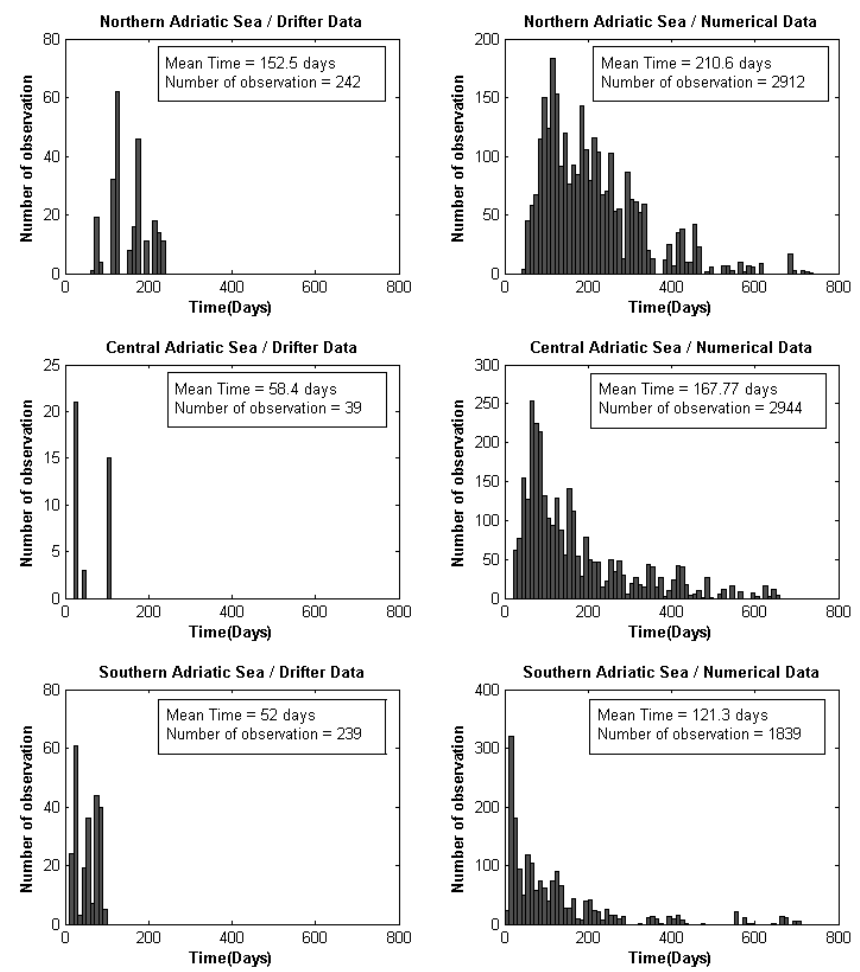

Fig. 2. Example of transit time pdfs computed from numerical (right) and real (left) particles starting in the selected areas shown in Fig. 1b in the northern (top), central (middle) and southern (bottom) Adriatic and leaving the Adriatic Sea through the western Otranto Channel.

of 135 days. The standard deviation around these values (not shown) vary essentially between 20 and 165 days. For the real drifters, mean transit times from the Otranto Channel are significantly lower and are bounded by 150 days. Maximal values appear in the open central Adriatic. In the WAC south of Gargano values are near 100 days, which is the same order of magnitude as with the numerical particles.

Finally the residence time, $T^{*}$, was estimated from the real drifters and numerical particles (Fig. 6 and Table 1). For the real drifters, $T^{*}$ was calculated using only the 83 drifters that exited through the Otranto Channel. Saturation occurs after 150 days and the residence time $T$ is about 70 days. In contrast, with numerical particles, $T^{*}$ reaches 168 days after the maximum integration period of the particles (750 days). The rate of change of $T^{*}$ at 750 days is equal, by taking the temporal derivative of the definition in Eq. (4), to the percentage of particles remaining in the basin, i.e., $(1000-986) / 1000=1.4 \%$. Thus, $T^{*}$ appears to asymptote to a constant value near 170 days. We have checked that the numerical drifter population is decaying quasi-exponentially. Theory shows that for an exponentially decaying population, the residence time converges, as time increases, to a constant value equal to the half life divided by $\ln (2)$. Hence, the half
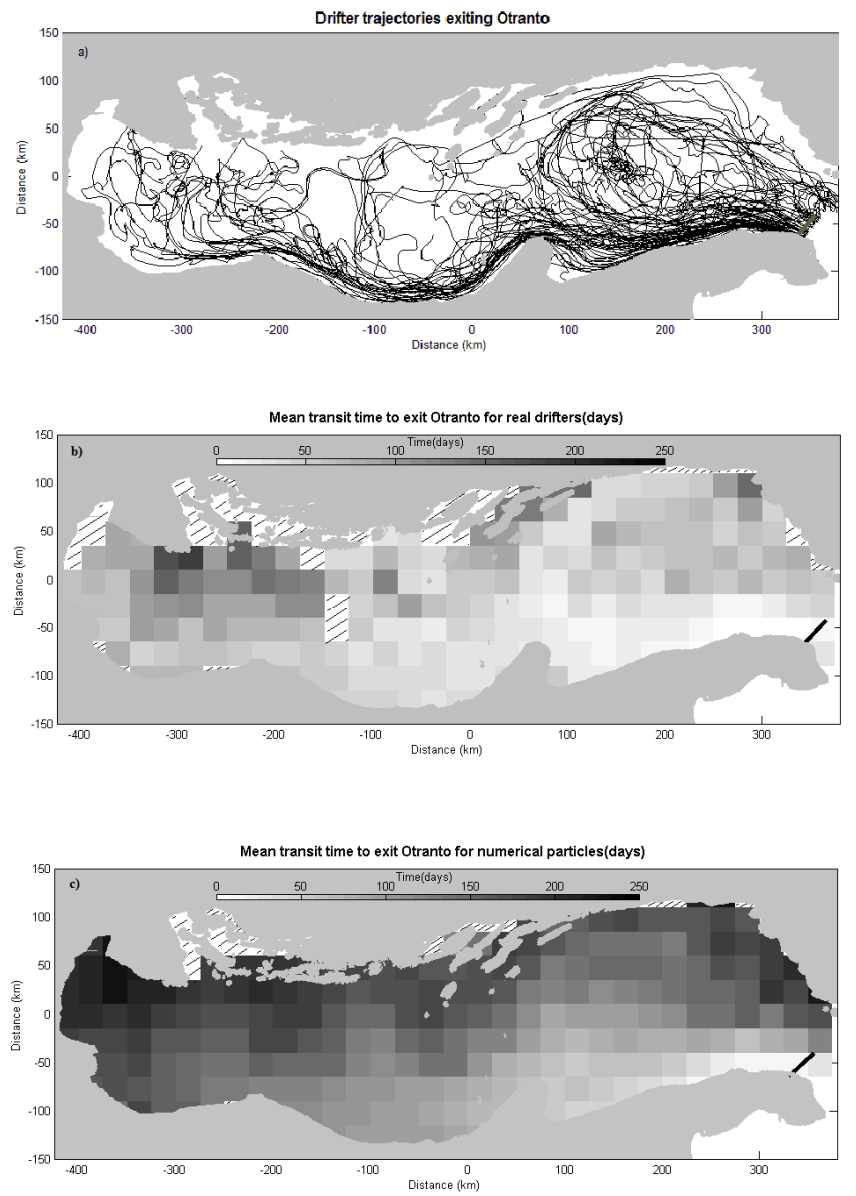

Fig. 3. Trajectories of the real drifters exiting the Adriatic Sea (a). Geographical distribution of the mean transit times to exit via the western Otranto Channel (through section shown with black line) estimated from real drifters (b) and numerical particles (c).

life of the numerical particles in the Adriatic Basin is about 120 days.

In order to assess the sensitivity of the transit and residence time results, we have also integrated the particles with a random flight model whose parameters correspond to the values found by Ursella et al. (2006) for the northern and central Adriatic. Values of $\sigma_{x}^{2}=77 \mathrm{~cm}^{2} \mathrm{~s}^{-2}, \sigma_{y}^{2}=51 \mathrm{~cm}^{2} \mathrm{~s}^{-2}, T_{\mathrm{L}}=$ 1.3 days yield the following results: mean transit time between the area off Istria (northern Adriatic) and the western Otranto Channel of 216 days, and residence time of 150 days. If the numerical particles are only advected by the mean flow (case of no "turbulence"), the mean transit between the northern Adriatic and Otranto areas is about 100 days, and the residence time is about 250 days. Numerical particles were also integrated over 1000 days yielding slightly superior values. Transit times between the entrance and exit through the Otranto Channel were also considered. A mean value of 130 days was found for the case without "turbulence" whereas 

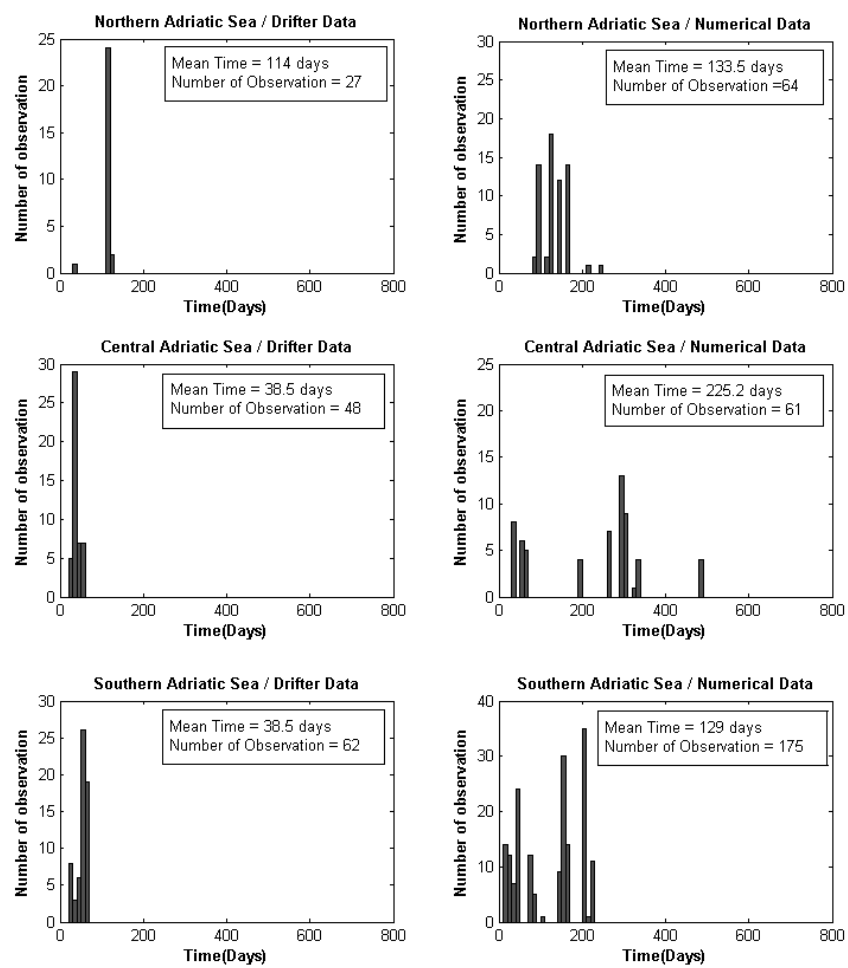

Fig. 4. Same as Fig. 2 but for the drifters entering through the eastern section of the Otranto Channel and reaching the areas depicted with squares in Fig. 1b.

the other simulations yielded values of 170-185 days. All the statistical results are summarized in Table 1.

\section{Discussion and conclusions}

Residence and transit times for the Adriatic surface circulation have been estimated from real data provided by satellitetracked drifters and from tracks of numerical particles integrated with a simple statistical Lagrangian model. The results obtained with the real drifters are systematically underestimated due to the limited operating period of the drifters. In fact, drifters in the Adriatic Sea have a typical half life of 3540 days (Poulain, 2011; Ursella et al., 2006), which can be less than some transit times and less than the residence time in the basin. As a result, transit time pdfs are significantly biased or skewed towards low values. In addition, the statistical results can also be dependent on the specific deployment locations. In contrast, with the tracks of numerical particles integrated for a long period (750 days) with a statistical Lagrangian model whose foundation is based on the real drifter results (in terms of mean flow and eddy kinetic energy or diffusivity levels) one can control the deployment array (e.g, uniform throughout the basin), the lifetime (750 days with no mortality and no stranding), and the number (1000) of particles. Using a simple advection-dispersion model, we have
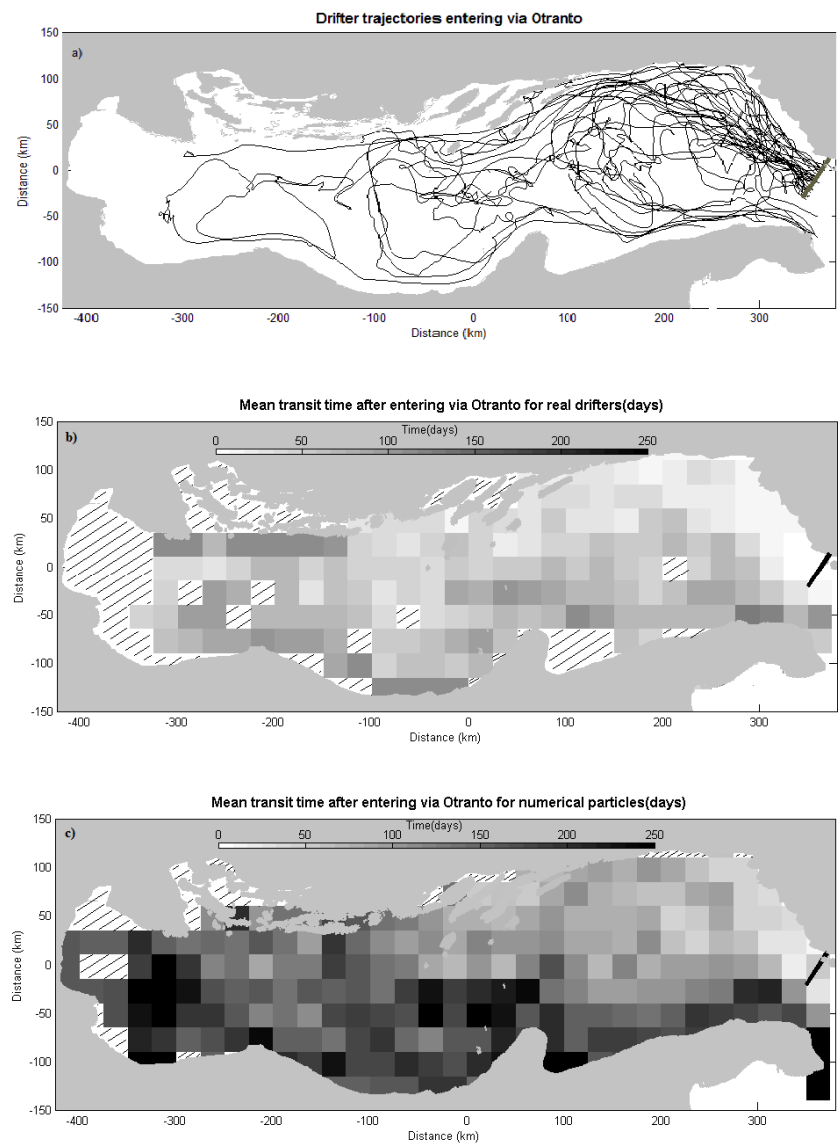

Fig. 5.

Fig. 5. Trajectories of the real drifters entering the Adriatic Sea (a). Geographical distribution of the mean transit time after entering on the eastern side of the Otranto Channel (through section shown with black line), estimated from real drifters (b) and numerical particles (c).

obtained new, and probably more accurate and robust, results for the transit times of objects (water particles, pollutants, oil spills, persons, etc.) in the Adriatic Sea under the influence of the near-surface currents, and to a lesser extent, of the local winds. For instance, we have found that the maximum mean time to exit the basin is 216-260 days for objects released in the very northern Adriatic, and that in the mean sense, a particle entering the Adriatic through the eastern Otranto Channel will exit the basin on the other side of the channel after about 170-185 days. We have also estimated that the residence time, which is the mean time a particle randomly deployed in the Adriatic stays in the basin before exiting, is 150-168 days. This value is lower than 200 days, the estimate of Falco et al. (2000) using numerical simulations of drifters released in the vicinity of the eastern Otranto Channel. This discrepancy is mostly due to the different deployment strategy: here numerical particles are deployed uniformly throughout the basin, and those caught in the fast WAC probably contribute 


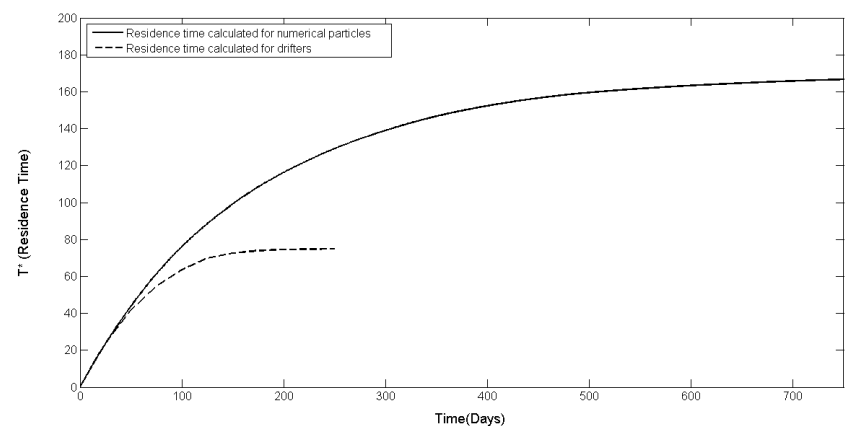

Fig. 6. Residence time $T^{*}$ versus time estimated from the real drifters and the numerical particles.

to reduce the residence time. The half life of 120 days corresponding to our numerical drifter population in the Adriatic Sea was found significantly longer than the half life of the real drifters $(\sim 40$ days $)$ operated in this marginal sea.

More accurate surface transit and residence times could be estimated by considering numerical simulations with spacedependent and non-isotropic velocity variance, integral time scale and diffusivity, as it is known that these values vary significantly in the basin and also with the proximity of the coast (see for example Ursella et al., 2006). The transport statistics could also be estimated for the different seasons of the year since the Adriatic circulation is known to vary seasonally (Poulain, 2001). Here, the seasonal signal has been included in the "turbulent" fluctuations of the Lagrangian statistical model, and hence, has some mean effect on the transit and residence time results. Considering seasonality as a deterministic signal can be a complicated and useless endeavor and better results are not guaranteed. It is proposed instead to use high-resolution hydro-dynamical models of the Adriatic circulation, possibly tuned in order to have the same mean flow and energy levels as the drifters, to integrate numerical particles in time-dependent velocity fields and compute Lagrangian statistics such as the transit and residence times.

Acknowledgements. We would like to thank all the people who contributed to the construction of the drifter database in the Adriatic, by deploying and recovering drifters, by processing the drifter data, or by simply making their data available to us. Special thanks to Alessandro Crise for insightful discussions. Special thanks to the two anonymous reviewers for providing constructive comments that helped to improve the original manuscript.

Edited by: E. J. M. Delhez

\section{References}

Buffoni, G., Falco, P., Griffa A., and Zambianchi, E.: Dispersion processes and residence times in a semi-enclosed basin with recirculating gyres: An application to the Tyrrhenian Sea, J. Geophys. Res., 102, 18699-18713, doi:10.1029/96JC03862, 1997.
Castellari, S., Griffa, A., Ozgokmen, T., and Poulain, P.-M.: Prediction of particle trajectories in the Adriatic Sea using Lagrangian data assimilation, J. Mar. Syst., 29, 33-50, 2001.

Choukroun, S., Ridd, P. V., Brinkman, R., and McKinna, L. I. W.: On the surface circulation in the western Coral Sea and residence times in the Great Barrier Reef, J. Geophys. Res, 115, C06013, doi:10.1029/2009JC005761, 2010.

Davidson, F. J. M., Allen, A., Brassington, G. B., Breivik, O., Daniel, P., Kamachi, M., Sato, S., King, B., Lefevre, F., Sutton M., and Kaneko K.: Applications of GODAE ocean current forecasts to search and rescue and ship routing, Oceanogr., 22, 176181, 2009.

Davis, R. E.: Drifter observation of coastal currents during CODE. The method and descriptive view, J. Geophys. Res., 90, 47414755, 1985.

Falco, P., Griffa, A., Poulain, P.-M., and Zambianchi, E.: Transport properties in the Adriatic Sea as deduced from drifter data, J. Phys. Oceanogr., 30, 2055-2071, 2000.

Hansen, D. V. and Poulain, P.-M.: Processing of WOCE/TOGA drifter data. J. Atmos. Oceanic Tech., 13, 900-909, 1996.

Hare, J. A., Churchill, J. H., Cowen, R. K., Berger, T. J., Cornillon, P. C., Dragos, P., Glenn, S. M., Govoni, J. J., and Lee, T. N.: Routes and rates of larval fish transport from the southeast to the northeast United States continental shelf, Limnol. Oceanogr., 47, 1774-1789, 2002.

Hays, G. C., Fossette, S., Katselidis, K. A., Mariani P., and Schofield, G.: Ontogenetic development of migration: Lagrangian drift trajectories suggest a new paradigm for sea turtles, J. R. Soc. Interface, 7, 1319-1327, 2010.

Haza, A., Ozgokmen, T., Griffa, A., Molcard, A., Poulain, P.M., and Peggion, G.: Transport properties in small-scale coastal flows: relative dispersion from VHF radar measurements in the Gulf of La Spezia, Ocean Dynam., 60, 861-882, 2010.

Holzer, M. and Hall, T. M.: Transit-time and tracer-age distribution in Geophysical flows. J. Atmos. Sci., 57, 3539-3558, 2000.

Jordi, A., Ferrer, M. I., Vizoso, G., Orfila, A., Basterretxea, G., Casas, B., Alvarez, A., Roig, D., Garau, B., Martinez, M., Fernandez, V., Fornes, A., Ruiz, M., Fornos, J. J., Balaguer, P., Duarte, C. M., Rodriguez, I., Alvarez, E., Onken, R., Orfila, P., and Tintore, J.: Scientific management of Mediterranean coastal zone: A hybrid ocean forecasting system for oil spill and search and rescue operations. Mar. Pollut. Bull., 53, 361-368, 2006.

Lacorata, G., Aurell., E., and Vulpiani, A.: Drifter dispersion in the Adriatic Sea: Lagrangian data and chaotic model, Annales Geophysicae, 19, 121-129, 2001.

Monsen, N. E., Cloern, J. E., Lucas, L. V., and Monismith, S. G.: A comment on the use of flushing time, residence time, and age as transport time scales, Limnology and Oceanography, 47, 15451553, 2002.

Niiler, P. P., Maximenko, N. A., and McWilliams, J. C.: Dynamically balanced absolute sea level of the global ocean derived from near-surface velocity observations, Geophys. Res. Lett., 30, 2164, doi:10.1029/2003GL018628, 2003.

Poulain, P.-M.: Drifter observations of surface circulation in the Adriatic Sea between December 1994 and March 1996, J. Mar. Syst., 20, 231-253, 1999.

Poulain, P.-M.: Adriatic Sea surface circulation as derived from drifter data between 1990 and 1999, J. Marine Sys., 29, 3-32, 2001. 
Cushman-Roisin, B., Gacic, M., Poulain, P.-M., and Artegiani, A.: Circulation, in "Physical oceanography of the Adriatic Sea", edited by: Cushman-Roisin, B., Gacic, M., Poulain, P.-M., and Artegiani, A., Kluwer, Kluwer Academic Publishers, Dordrecht, the Netherlands, 67-109, 2001.

Poulain, P.-M., Gerin, R., Mauri, E., and Pennel, R.: Wind Effects on Drogued and Undrogued Drifters in the Eastern Mediterranean, J. Atmos. Oceanic Technol., 26, 1144-1156, 2009.

Poulain, P.-M., Menna, M., and Mauri, E.: Surface geostrophic circulation of the Mediterranean Sea derived from drifter and satellite altimeter data, J. Phys. Oceanogr., 42, 973-990, 2012.

Takeoka, H.: Fundamental concepts of exchange and transport time scales in a coastal sea, Cont. Shelf Res., 3, 331-326, 1984.
Thompson, D. J.: A random walk model of dispersion in turbulent flows and its application to dispersion in a valley, Quart. J. Roy. Meteor. Soc, 112, 511-530, 1986.

Ursella, L., Poulain, P.-M., and Signell R. P.: Surface drifter derived circulation in the northern and middle Adriatic Sea: Response to wind regime and season, J. Geophys. Res., 111, C03S04, doi:10.1029/2005JC003177, 2006.

Veneziani, M., Griffa, A., and Poulain, P.-M.: Historical drifter data and statistical prediction of particle motion: A case study in the central Adriatic Sea, J. Atmos. Ocean. Tech., 24, 235-254, 2007. 